\title{
THE RATE OF ATTAINMENT OF DIFFUSION EQUILIBRIUM FOR THIOCYANATE BETWEEN PLASMA AND TRANSUDATES FOL- LOWING THE INTRAVENOUS INJECTION OF SODIUM THIOCYANATE IN PATIENTS WITH EDEMA
}

\author{
By D. ROURKE GILLIGAN AND MARK D. ALTSCHULE \\ (From the Medical Research Laboratories of the Beth Israel Hospital, and the Department of \\ Medicine, Harvard Medical School, Boston)
}

(Received for publication Feb. 28, 1939)

Estimations of the volume of extracellular fluid in man have been made by calculating the volume of body fluid through which thiocyanate is distributed after the intravenous administration of sodium thiocyanate $(1,2,3)$. In the method as proposed, a known amount of sodium thiocyanate in solution is administered intravenously and blood is drawn for the measurement of the concentration of thiocyanate in the serum 1 or 2 hours after the injection $(1,2)$. It has been demonstrated in normal man that the distribution of thiocyanate is rapid and that diffusion equilibrium is attained within 1 hour after injection $(1,2,3)$.

The time required for the attainment of equilibrium for CNS after intravenous injection of $\mathrm{NaCNS}$ in patients with edema has not been established; the present report affords information on this problem. Measurement of the CNS concentrations of serum and edema fluid has been made on samples drawn simultaneously at various times after intravenous injection of $\mathrm{NaCNS}$.

To establish the time required for attainment of equilibrium by analyses of transudate and serum it was necessary to know what the concentration of CNS in a transudate should be, in relation to the concentration in the serum, in a given system at equilibrium. Lavietes, Bourdillon, and Klinghoffer (2) observed in a few experiments in edematous patients that the concentration of CNS in the serum was from 5 to 21 per cent higher than in the transudate at equilibrium, when samples were drawn 12 to 64 hours after the administration of CNS. These authors suggest that CNS may combine in some manner with protein. Studies of the protein concentrations of serum and transudate have been made in each instance in the present study, and the difference in CNS concentration between serum and transudate in each case has been analyzed in respect to the difference in protein concentration.

\section{MATERIAL AND METHODS}

Twenty-three studies have been made in 13 patients with edema caused by congestive heart failure, cirrhosis of the liver, carcinoma, hepatic vein thrombosis, or vena caval obstruction. In 8 studies edema fluid was obtained from the abdomen, in 7 from the thoracic cavity, in 8 from the subcutaneous spaces. Subcutaneous edema fluid was removed by means of Southey's tubes.

From 15 to 20 cc. of 5 per cent sterile solution of $\mathrm{NaCNS}$ was injected intravenously in approximately 3 minutes, the amount depending on the body weight of the patient and the estimated volume of edema fluid. Samples of blood and edema fluid were obtained simultaneously from 1 to 28 hours after the intravenous injection of NaCNS; in several instances, 2 or more samples of blood and fluid were drawn at various times after an injection. The concentrations of CNS in the sera and transudates and in urine were measured as described by Lavietes, Bourdillon, and Klinghoffer (2).

Before the data could be applied to the study of the rate of attainment of equilibrium, it was necessary to determine the nature of the distribution of CNS when equilibrium is reached. The distribution of CNS in relation to the distribution of protein between the sera and fluids was investigated from this point of view. The total protein concentrations of sera and transudates were estimated from specific gravity measurements made according to Moore and Van Slyke (4), using 5 cc. specific gravity bottles. The formula,

Grams of total protein per 100 cc. $=343(G-1.007)$, 
where $G$ represents specific gravity, was employed (4). ${ }^{1}$

The "available fluid" for CNS distribution (1) was calculated by the formula,

Liters of " available fluid" =

mgm. of CNS in body

mgm. of CNS per liter of serum

1 This formula was applied by Moore and Van Slyke (4) to plasma analyses. Analysis of data obtained earlier in this laboratory (5) demonstrates that the formula is applicable to approximate estimations of the protein concentrations of edema fluids. The values were available for protein concentrations as measured by the macroKjeldahl method, and for specific gravity as measured according to Moore and Van Slyke, in 22 thoracic or abdominal fluid specimens. In this series the average protein concentration was 2.03 grams per $100 \mathrm{cc}$, the limits being 0.6 to 4.4 grams per $100 \mathrm{cc}$. As calculated from the specific gravity values, employing the formula above, the average estimated protein concentration was
From this value and the surface area of the patient the liters of " available fluid" per square meter of body surface were calculated. The amount of CNS in the body was calculated from the amount injected minus the amount which had been excreted in the urine up to the time of withdrawal of the sample of blood. The amounts excreted in the urine were variable, but small, for the periods of study of 11 hours or less; the greatest excretion rate was $30 \mathrm{mgm}$. in 6 hours.

\section{RESULTS}

After the intravenous injection of $\mathrm{NaCNS}$ the concentration of CNS increased slowly in the transudates of patients of this study, as shown by serial samplings of transudate and blood in 4 cases (Figure 1).

2.00 grams per $100 \mathrm{cc}$. The standard deviation of the differences between the 2 methods was 0.25 .

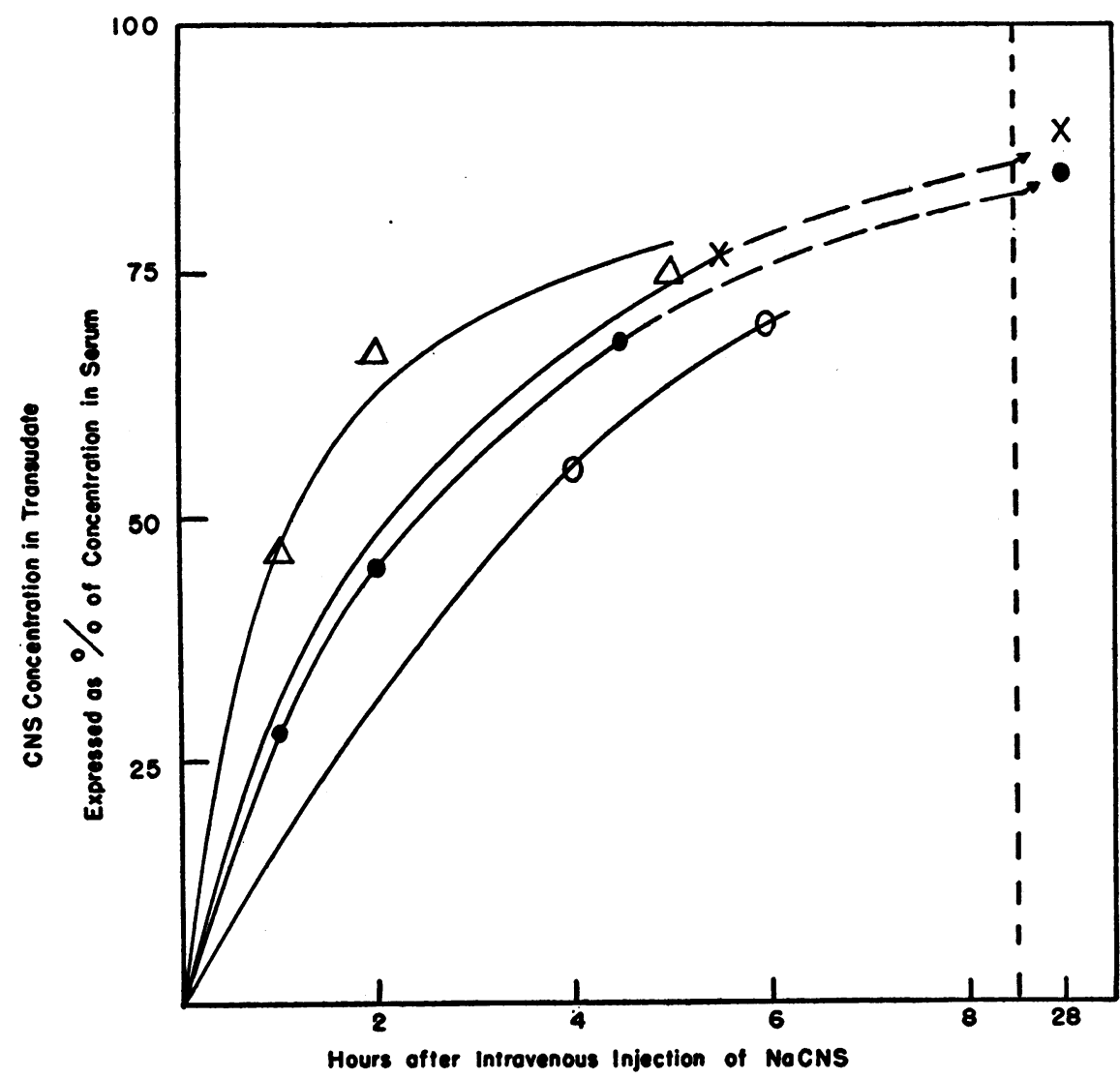

Fig. 1. Rate of Approach to Diffusion Equilibrius for CNS as Shown by Analyses of Serial Serum and Edema flutd Samples Drawn in 4 Patients at Various Times following Intravenous Injection of NaCNS 
In 5 cases in which samples of transudate and blood were drawn from 8.5 to 28 hours after the intravenous injection of $\mathrm{NaCNS}$ the $\mathrm{CNS}$ concentrations in the sera ranged from 1 to 20 per cent higher than the concentrations in the corresponding transudates (Figure 2). In 2 of these experiments subcutaneous edema fluid was studied, in 2, chest fluid, and in 1, ascitic fluid. The protein concentrations in the sera in these cases varied from 1.3 to 5.5 grams per $100 \mathrm{cc}$. higher than in the corresponding transudates. When the concentration of CNS in the transudates, expressed as the per cent of the concentration in the corresponding sera, is plotted against the excess concentration of protein in the sera (grams of serum protein per $100 \mathrm{cc}$. minus grams of transudate protein per $100 \mathrm{cc}$.) a straight line relationship is observed in these 5 cases (Figure 2-letters $\mathrm{C}$ ).

In 2 of 3 cases studied 6 hours after the injection of CNS, the concentrations of CNS in the sera were 5 and 12 per cent higher than in the transudates. The same relationship to the protein values existed in these cases as in those above described (Figure 2) ; it may be inferred, then, that equilibrium was attained also in these 2 instances. In the other case studied after 6 hours the relative concentration of CNS in the transudate was considerably lower than that expected at equilibrium (Figure 1, Case A). Of the 9 studies made from 3.5 to 5.5 hours after injection, equilibrium had been attained in only 3 (Figure 2). Equilibrium was not attained in any of the 6 experiments in which 1 to 3 hours elapsed between injection and sampling. A summary of all these findings is given in Figure 3.

In several of the studies made on samples drawn 5.5 hours or less after the injection of $\mathrm{NaCNS}$, the CNS concentrations in the transudate were so low as to indicate that equilibrium would not have been attained until 8 to 10 hours after the injection. For example, in 2 patients with ascites from whose abdomens 6 and 7 liters of fluid were drawn, the concentrations of CNS in the ascitic fluids 4 hours after administering $\mathrm{NaCNS}$ were only 50 and 55 per cent of the

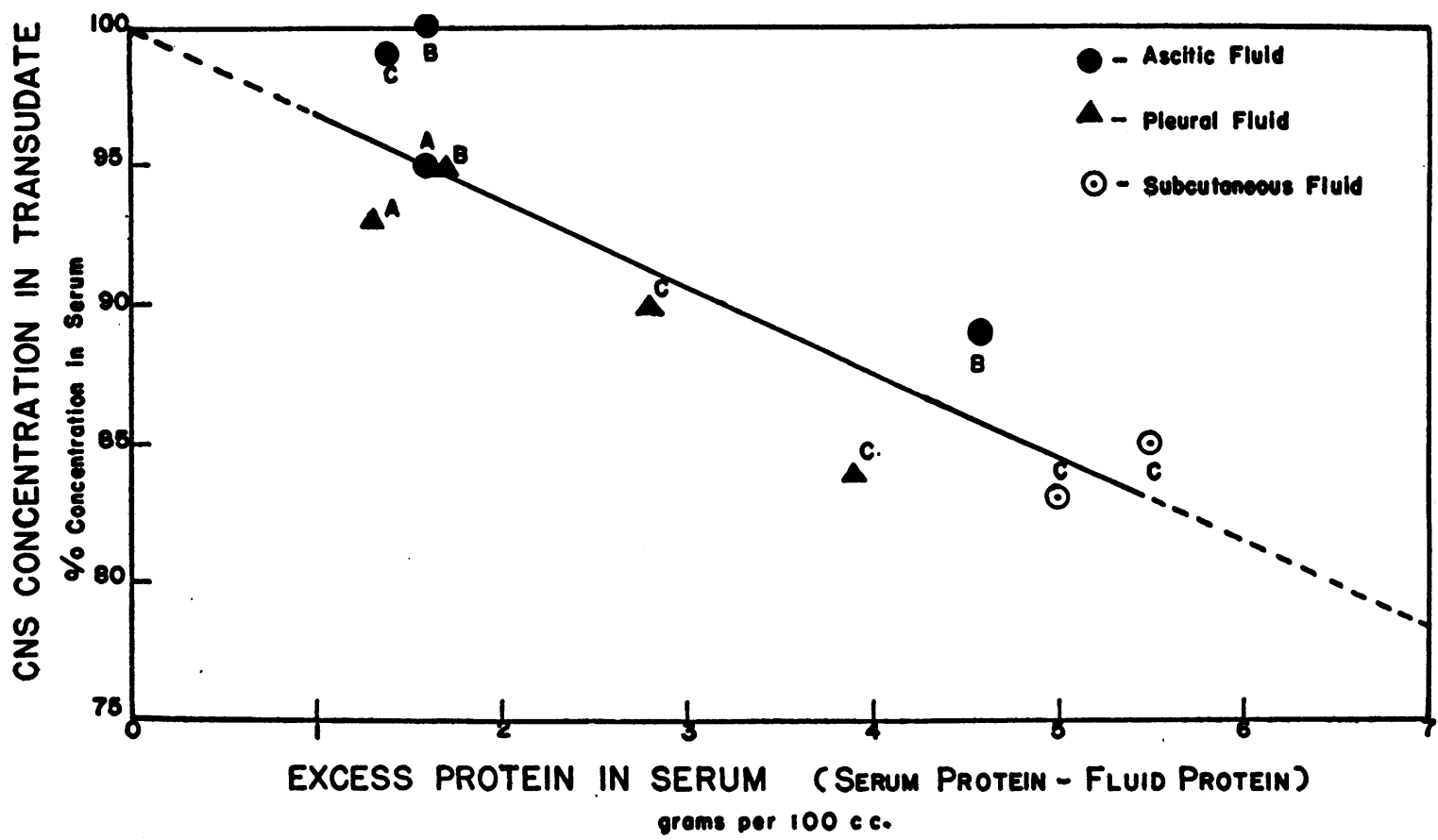

Fig. 2. Rerationship betwegn the Difference in Protein Concentration in Serum and Transudate and the Difference in the CNS Concentration of Serum and Transudate

The letters refer to the time elapsed between intravenous injection of $\mathrm{NaCNS}$ and collection of samples: $A=$ 4.0 to 4.5 hours, $B=5.5$ to 6.0 hours, $C=8.5$ to 28 hours. 


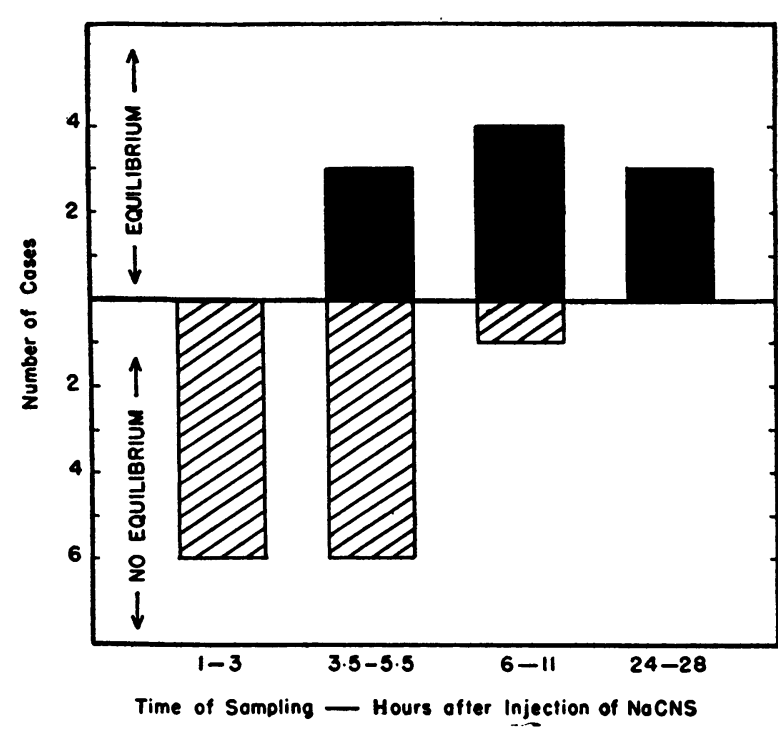

Fig. 3. Time Required for Attainment of DiffuSION EQUILIbrium For CNS in Various Edematous Deposits, Following the Intravenous InJection of NaCNS in Patients with Edema

concentrations in the sera. Distribution was complete in a shorter time in patients with smaller amounts of ascites.

Approximate equality of the concentrations of CNS in two blood samples drawn 2 hours and 4 hours after the injection of $\mathrm{NaCNS}$ was observed in 2 instances in which the edema fluid sample drawn at 4 hours showed a CNS concentration lower than that to be expected at equilibrium.

The " available fluid" for CNS distribution in the experiments in which equilibrium had been reached varied from 29 to 59 per cent of the body weights of the patients, or from 11 to 24 liters per square meter of body surface. These values are to be contrasted with the reported normal values of 24 per cent of body weight, or 9.5 liters per square meter of body surface (1). The smallest increases above the normal in "available fluid" were obtained in patients with carcinomatous lymphatic obstruction limited to one pleural space, the greatest increases were observed in patients with congestive heart failure and generalized anasarca.

\section{DISCUSSION}

The above data demonstrate that diffusion equilibrium for CNS usually is not attained in ede- matous patients with large volumes of fluid in the thoracic, abdominal, or subcutaneous spaces until 6 to 10 hours following the intravenous injection of CNS. The shortest time observed for the establishment of equilibrium was 4 hours; in this instance fluid in the thoracic cavity of a patient with carcinomatous obstruction was studied.

The time required for attainment of diffusion equilibrium for $\mathrm{CNS}$ in a given body cavity depended upon the volume of edema in that space. It is true, probably, that equilibrium is reached more quickly in a patient with a given amount of edema spread over the several body compartments available for extracellular fluid deposits, than in a patient with a similar or even somewhat lesser total amount of edema which is contained mainly in the abdominal or thoracic cavity. Obviously equilibrium would be attained more rapidly than observed here in edematous patients with lesser amounts of fluid than those of this study, and more slowly in patients with greater edematous deposits.

Because of the above considerations it is suggested that in routine studies of the amount of "fluid available" for the distribution of CNS in edematous patients, blood for serum CNS measurement should not be drawn until 12 to 24 hours after the intravenous administration of the salt; this period is probably also of sufficient duration when the salt is administered orally. Under these conditions the amount of CNS excreted in the urine should be measured. The approximate equality of concentration of CNS in serial samples of serum drawn at 2-hour intervals following injection, does not necessarily imply that equilibrium has been attained throughout the body in patients with edema. The concentration in a transudate increases slowly during the later period of equilibration (Figure 1); the CNS thus entering a given edematous deposit may be obtained not only from the blood but also from the more quickly equilibrated extracellular spaces in less edematous parts of the body. The decrease in CNS concentration of the blood under these circumstances, therefore, would be relatively small over a period as short as 1 to 2 hours.

In the cases of this study in which equilibrium was attained, the concentrations of $\mathrm{CNS}$ of the sera ranged from 0 to 20 per cent higher than 
those of the corresponding transudates. The data of Figure 2 suggest that the excess CNS in the serum, as compared with that in the transudate, may be related to the higher concentration of protein in the serum $;^{2}$ that this relationship might exist was suggested previously by Lavietes, Bourdillon, and Klinghoffer (2). Conceivably, CNS may be bound by some other component of the serum which is distributed between plasma and transudate in a manner like protein. It has been suggested (2) that the lower concentration of CNS in extracellular fluid be considered in calculations of extracellular fluid volume. However, since the ratio of concentration of CNS in extracellular fluid to that in serum in normal man cannot be established directly, and further, since this ratio is variable in patients with edema, and, undoubtedly even in different compartments in a given patient with edema, the authors do not consider such a correction valid. Thiocyanate enters the red blood cells but does not enter other cells in the body $(1,2,3)$. It has been suggested that a correction be made in calculating extracellular fluid volume for the CNS contained in the red blood cells (2) ; this correction could not be applied in patients with edema and abnormal blood volumes unless the blood volumes were accurately measured. For these reasons we have calculated simply the "available fluid" for distribution of CNS as originally suggested by Crandall and Anderson (1) (see methods).

It has been noted in normal man that CNS is distributed in the body somewhat more rapidly than sucrose or sulfate (2). Likewise, the comparative rate of distribution of various substances in patients with edema undoubtedly varies with the coefficient of diffusion of the substance. It has been pointed out that because of the relatively slow diffusion rate and the rapidity of excretion of sulfate and sucrose from the body, these substances cannot be used to measure extracellular fluid volume in patients with edema (2).

In all studies of the distribution of substances at equilibrium between plasma and transudates in

\footnotetext{
2 A closer correlation than appears in Figure 1 might be evidenced if the concentrations of protein were measured directly by the Kjeldahl method, instead of calculated from measurements of specific gravity; further, the relationship may be affected by the proportions of excess albumin or globulin.
}

edematous patients the relatively long time required for the attainment of diffusion equilibrium must receive consideration. It was observed earlier by one of us (5) that the concentration of glucose in the water of transudates of edematous patients was sometimes higher than than that in the water of the serum after a fast of 12 or some few more hours; the greatest differences were observed in edematous diabetic patients. This finding was attributed to the absence of diffusion equilibrium for glucose, referable to the time required for equilibration, and the relatively great variations in blood sugar which occur rapidly, particularly in diabetic patients (5).

\section{SUMMARY AND CONCLUSIONS}

1. In the patients of this study with large accumulations of edema fluid due to various diseases, diffusion equilibrium for CNS between plasma and transudates in the subcutaneous, thoracic, or abdominal cavities usually was not attained until 6 to 10 hours after the intravenous injection of $\mathrm{NaCNS}$. This finding is contrasted to the observation that diffusion equilibrium for CNS obtains in normal subjects within one hour after the injection of $\mathrm{NaCNS}$.

2. The time required for attainment of diffusion equilibrium for CNS between plasma and the edema fluid in a given body compartment appears to be directly proportional to the volume of transudate in that compartment.

3. At equilibrium, the concentrations of CNS in the sera were from 0 to 20 per cent higher than the concentrations in the transudate. Studies of the relative concentrations of protein in sera and transudates indicate that some CNS is "bound" by protein or some other relatively non-diffusible substance.

4. It is suggested that in routine studies of the amount of " available fluid" for CNS distribution in edematous patients, 12 to 24 hours should elapse between the administration of the CNS and the drawing of blood for measurement of the CNS concentration in the serum.

5. In all studies of the distribution of substances at equilibrium between plasma and transudates in edematous patients, the relatively long time required for the attainment of diffusion equilibrium must receive consideration. 


\section{BIBLIOGRAPHY}

1. Crandall, L. A., Jr., and Anderson, M. X., Estimation of state of hydration of body by amount of water available for solution of sodium thiocyanate. Am. J. Digest. Dis. and Nutrition, 1934, 1, 126.

2. Lavietes, P. H., Bourdillon, J., and Klinghoffer, K. A., Volume of extracellular fluids of body. J. Clin. Invest., 1936, 15, 261.

3. Stewart, J. D., and Rourke, G. M., Changes in blood and interstitial fluid resulting from surgical op- eration and ether anesthesia. J. Clin. Invest., 1938, $17,413$.

4. Moore, N. S., and Van Slyke, D. D., Relationships between plasma specific gravity, plasma protein content, and edema in nephritis. J. Clin. Invest., 1930, 8, 337.

5. Gilligan, D. R., Volk, M. C., and Blumgart, H. L., Observations on chemical and physical relation between blood serum and body fluids; nature of edema fluids and evidence regarding mechanism of edema formation. J. Clin. Invest., 1934, 13, 365. 